\title{
Socioeconomic gradients and mental health: implications for public health
}

Sarah Stewart-Brown, Preshila Chandimali Samaraweera, Frances Taggart, Ngianga-Bakwin Kandala and Saverio Stranges

\section{Background}

Research on mental well-being is relatively new and studies of its determinants are rare.

\section{Aims \\ To investigate whether the socioeconomic correlates of mental well-being mirror those for mental illness.}

\section{Method}

Using logistic regression analyses, the independent odds ratios of high and low mental well-being, compared with middle-range mental well-being, were estimated for a number of sociodemographic variables known to be associated with mental illness from 13983 participants in the 2010 and 2011 Health Surveys for England.

\section{Results}

Independent odds ratios for low mental well-being were as expected from studies of mental illness with increased odds for the unemployed $(\mathrm{OR}=1.46,95 \% \mathrm{Cl} 1.01-2.10)$ and those aged 35-54 years $(\mathrm{OR}=1.58,95 \% \mathrm{Cl} 1.35-1.84)$ and reduced odds for the married $(\mathrm{OR}=0.78,95 \% \mathrm{Cl} 0.62-0.97)$. A linear trend was observed with education and equivalised income. Odds ratios for high mental well-being differed from those for low mental well-being with regard to age (55+ years: $\mathrm{OR}=1.48,95 \% \mathrm{Cl} 1.23-1.79)$; employment status where there was an association only with retirement $(\mathrm{OR}=1.35,95 \% \mathrm{Cl}$ 1.09-1.69); education where there was no association; and equivalised income for which the association was non-linear

\section{Conclusions}

Odds ratios for low mental well-being mirrored those for mental illness, but not those for high mental well-being, suggesting that the socioeconomic factors associated with positive mental health are different from those associated with mental illness.

\section{Declaration of interest}

S.S.-B. developed the Warwick-Edinburgh Mental Well-being scale, but has no financial interests in the scale.

\section{Copyright and usage}

(c) The Royal college of Psychiatrists 2015.
The case for the promotion of positive mental health or mental well-being has been made convincingly on both health ${ }^{1}$ and economic grounds ${ }^{2}$ and, as a consequence, mental well-being now assumes an important place in mental health and public health policy. ${ }^{3-5}$ Key features of mental well-being are that it creates resilience to both mental and physical illness, increases longevity in general populations, ${ }^{6}$ increases educational achievement and enhances performance in the workplace. ${ }^{1}$ The World Health Organization (WHO) describes mental well-being as a state in which the individual realises his or her own abilities, copes with the normal stresses of life, works productively and makes a contribution to his or her community. ${ }^{7}$ Mental well-being is widely recognised as extending beyond the absence of mental illness and comprising both affective components (emotions/ feelings) and psychological functioning. ${ }^{1}$ Arguments have been advanced that mental well-being and mental illness may represent two different but correlated continua. In this case mental wellbeing can be positive or negative and low mental well-being is not synonymous with mental illness. For clarity we have referred in this paper to low and high mental well-being and to mental illness and positive mental health, which we regard as synonymous with high mental well-being. Effective public health practice demands a sound understanding of the determinants not only of illness but also of positive states of health. Whereas mental illness is distributed according to familiar social gradients ${ }^{8,9}$ with a high prevalence among deprived groups and those living in poverty, less is known about the social determinants of positive mental health. There is some indication that the distribution is different from that for mental illness. ${ }^{1}$ The Health Survey for England $(\mathrm{HSE})^{10}$ collected data on mental well-being in 2010 and 2011, making it possible to assess socioeconomic gradients of high and low mental well-being in a large representative sample of the English population and to test the hypothesis that these gradients are different from those observed for mental illness.

\section{Method}

\section{Study population}

The HSE is an annual survey of a nationally representative population that samples adults and children in households at private residential addresses. ${ }^{10}$ In both 2010 and 2011, 66\% of households agreed to participate providing samples of 14112 (8420 age 16+ years) and 10617 (8610 age16+ years), respectively. Detailed information was collected on mental and physical health in relation to demographic and socioeconomic characteristics of adults and children. Regarding, ethical approval as the study design was of secondary data analysis using data collected in the HSE; permission to use the data was granted by the UK Data Service.

\section{Mental well-being}

The Warwick-Edinburgh Mental Well-being Scale (WEMWBS) ${ }^{11}$ was administered in English only to respondents over 16 years of age, a total of 17030 people across both years. The WEMWBS is a well validated, popular measure currently used to monitor mental well-being in the English public health outcomes framework ${ }^{12}$ and the Scottish Government's Mental Health Indicators data-set. ${ }^{13}$ It has been validated in a number of different cultural and linguistic settings including English-speaking minority ethnic groups in the UK. ${ }^{14,15}$ Valid responses were available for 13983 (82.1\%) of adult (16+ years) respondents for the combined 2010 and 2011 datasets. (See online Table DS1 for comparison of respondents and non-respondents). These were used to define three population 
groups: more than one standard deviation from the mean in either direction (top 15th centile: WEMWBS score 60-70; and bottom 15th centile: WEMWBS score 14-42) and the remainder (16-84th percentile: WEMWBS score 43-59). Valid responses were those in which all items in the scale had been completed. In the first series of models, odds ratios (ORs) were generated for the low well-being group compared with the middle-range group and in the second series for the high well-being group compared with the middle-range group.

\section{Sociodemographic correlates}

Sociodemographic variables known to be relevant to inequalities in mental illness and available in the HSE data-sets were included. These were: age (16-34, 35-54, 55+); gender; ethnicity (White, Indian and Pakistani (including mixed race), African-Caribbean and African (including mix race), Chinese and other Asian, and other); religion (none, Christian, Muslim, other); economic status (employed, unemployed seeking work, retired, economically inactive); marital status (single, married/civil partnership/ cohabitee, divorced/separated/widowed); educational attainment (NVQ4/NVQ5/degree or equivalent, secondary education to, NVQ3/GCE A-level equivalent, NVQ2/GCE O-level equivalent, NVQ1/CSE other grade equivalent, no qualification) and equivalised household income in quintiles. ${ }^{16}$ In order to maximise sample size and avoid bias, missing values were included for all covariates.

\section{Statistical analysis}

We used $\chi^{2}$-tests to determine the statistical significance of any difference in the distributions of the selected sociodemographic variables across categories of WEMWBS scores (low, middle, high) (online Table DS2). Data were analysed in logistic regression models in order to identify differences in the pattern of association of sociodemographic variables with high and low mental well-being. Unadjusted (Model 1), partially adjusted (age and gender) (Model 2) and fully adjusted (all variables) (Model 3) models were generated to calculate odds ratios of low mental well-being compared with middle-range (see Table 1 for the fully adjusted model and online Table DS3 for details of all three models), and high mental well-being compared with middle-range (see Table 2 for the fully adjusted model and online Table DS4 for details of all three models), using SPSS 21 for Windows for different levels of socioeconomic variables. The significance of linear trends and gender differences in the associations of low and high mental well-being were assessed for each of the correlates, the latter using tests for interaction (see online Tables DS5 and DS6, respectively).

\section{Results}

Significant differences were found for all characteristics of study participants with and without complete data except for gender (online Table DS1). Respondents were more likely to be young, married/cohabiting, employed, White, with higher levels of education, higher incomes and either no religion or Christian. In descriptive analyses, significant associations were evident by age, marital status, education, household income, religion, employment and ethnicity across the three categories of mental well-being (online Table DS2).

In the fully adjusted models for low mental well-being compared with middle-range (Table 1), middle age (35-54 years) was associated with an increased odds ratio $(\mathrm{OR}=1.58,95 \% \mathrm{CI}$ $1.35-1.84)$, whereas marriage/cohabitee status was associated with a reduced odds $(\mathrm{OR}=0.78,95 \% \mathrm{CI} 0.62-0.97)$. Education showed

\begin{tabular}{|c|c|}
\hline & $\begin{array}{l}\text { Fully adjusted OR } \\
\qquad(95 \% \mathrm{Cl})\end{array}$ \\
\hline \multicolumn{2}{|l|}{ Age, years } \\
\hline $16-34$ & Ref \\
\hline $35-54$ & $1.58(1.35-1.84)$ \\
\hline $55+$ & $0.96(0.77-1.18)$ \\
\hline \multicolumn{2}{|l|}{ Gender } \\
\hline Male & Ref \\
\hline Female & $1.04(0.68-1.58)$ \\
\hline \multicolumn{2}{|l|}{ Marital status } \\
\hline Single & Ref \\
\hline Married/civil partnership/cohabitees & $0.78(0.62-0.97)$ \\
\hline Separated/divorced/widowed & $1.24(0.92-1.68)$ \\
\hline \multicolumn{2}{|l|}{ Education $^{b}$} \\
\hline NVQ4/NVQ5/degree or equivalent & Ref \\
\hline Higher education below degree & $1.03(0.76-1.41)$ \\
\hline NVQ3/GCE A-Level equivalent & $1.28(0.96-1.72)$ \\
\hline NVQ2/GCE O-Level & $1.35(1.03-1.77)$ \\
\hline NVQ1/CSE other grade equivalent & $1.47(0.99-2.19)$ \\
\hline No qualification & $2.00(1.50-2.68)$ \\
\hline \multicolumn{2}{|l|}{ Equivalised income $\mathrm{b}^{\mathrm{b}}$} \\
\hline Highest ( $>$ £47 794.12) & Ref \\
\hline Second highest ( $>£ 27704.92$ to $\leqslant £ 47794.12$ ) & $0.92(0.70-1.22)$ \\
\hline Middle ( $>$ f19117.65 to $\leqslant £ 27704.92)$ & $1.24(0.94-1.63)$ \\
\hline Second lowest ( $>£ 11676.65$ to $\leqslant 19117.65$ ) & $1.40(1.05-1.87)$ \\
\hline Lowest $(\leqslant £ 11676.65)$ & $1.19(0.79-1.78)$ \\
\hline \multicolumn{2}{|l|}{ Employment } \\
\hline In employment & Ref \\
\hline Unemployed seeking work & $1.46(1.01-2.10)$ \\
\hline Retired & $1.11(0.85-1.47)$ \\
\hline Other economically inactive & $2.89(2.21-3.78)$ \\
\hline \multicolumn{2}{|l|}{ Religion } \\
\hline No religion & Ref \\
\hline Christian and other denominators & $1.02(0.85-1.24)$ \\
\hline Muslims & $0.67(0.30-1.53)$ \\
\hline Any other & $0.71(0.39-1.30)$ \\
\hline \multicolumn{2}{|l|}{ Ethnicity } \\
\hline White & Ref \\
\hline Indian and Pakistani & $0.73(0.35-1.53)$ \\
\hline African-Caribbean & $\mathbf{0 . 3 6}(0.19-0.66)$ \\
\hline Chinese and other Asian & $0.77(0.33-1.82)$ \\
\hline Other & $0.71(0.27-1.87)$ \\
\hline \multicolumn{2}{|c|}{$\begin{array}{l}\text { a. The univariate (Model 1) and partially adjusted (age and gender) (Model 2) odds } \\
\text { ratios can be found in online Table DS3. Low mental well-being defined as a } \\
\text { Warwick-Edinburgh Mental Well-being Scale (WEMWBS) score of 14-42 and middle- } \\
\text { range mental well-being as a WEMWBS score of } 43-59 \text {. The fully adjusted model } \\
\text { included: age, gender, marital status, education, equivalised income, employment, } \\
\text { religion and ethnic origin. } \\
\text { b. P-value for linear trend: } 0.001 \text {. }\end{array}$} \\
\hline
\end{tabular}

the expected dose-response relationships ( $P$-value for linear trend $<0.001)$ with significantly increased odds of low mental well-being among those with GCE O levels $(\mathrm{OR}=1.35,95 \% \mathrm{CI}$ $1.03-1.77)$ and those with no qualifications $(\mathrm{OR}=2.00,95 \% \mathrm{CI}$ 1.50-2.68) compared with those with a degree. Low mental well-being was linearly associated with equivalised income $(P<0.001)$ with increased odds for those in the second lowest income bracket $(\mathrm{OR}=1.40,95 \%$ CI $1.05-1.87)$ compared with the highest. Unemployment, both in those seeking work $(\mathrm{OR}=1.46,95 \%$ CI $1.01-2.10)$ and those inactive for other reasons $(\mathrm{OR}=2.89,95 \% \mathrm{CI} 2.21-3.78)$, increased the odds of low mental well-being. The African and African-Caribbean group was protected from low mental well-being $(\mathrm{OR}=0.36,95 \% \mathrm{CI}$ $0.19-0.66)$. There were no associations with religion or gender.

In the fully adjusted models for high mental well-being compared with middle-range (Table 2$)$ both older age (55+ years) $(\mathrm{OR}=1.48,95 \% \mathrm{CI} 1.23-1.79)$ and being retired $(\mathrm{OR}=1.35,95 \%$ 
Table 2 Fully adjusted (Model 3) odds ratios for high mental well-being referenced to middle-range mental well-being ${ }^{a}$

Fully adjusted $\mathrm{OR}$ $(95 \% \mathrm{Cl})$

\begin{tabular}{|cc|}
\hline Age, years $^{\mathrm{b}}$ & \\
$16-34$ & Ref \\
$35-54$ & $0.96(0.82-1.12)$ \\
$55+$ & $\mathbf{1 . 4 8}(1.23-1.79)$ \\
\hline Gender & Ref \\
Male & $0.95(0.64-1.41)$ \\
\hline Female &
\end{tabular}

$\begin{array}{lc}\text { Marital status } & \text { Ref } \\ \text { Single } & 1.01(0.80-1.28) \\ \text { Married/civil partnership/cohabitees } & 0.98(0.71-1.36) \\ \text { Separated/divorced/widowed } & \end{array}$

Education

NVQ4/NVQ5/degree or equivalent

Higher education below degree

NVQ3/GCE A-level equivalent

NVQ2/GCE O-level

NVQ1/CSE other grade equivalent

No qualification

Equivalised income

Highest ( $>£ 47794.12)$

Second highest $(>£ 27704.92$ to $\leqslant £ 47794.12)$

Middle ( $>$ f19117.65 to $\leqslant £ 27704.92)$

Second lowest ( $>£ 11676.65$ to $\leqslant 19117.65$ )

Lowest ( $\leqslant £ 11676.65)$

$0.98(0.71-1.36)$

Employment

In employment

Unemployed seeking work

Ref

$1.01(0.78-1.30)$

$1.04(0.81-1.34)$

$1.00(0.78-1.27)$

$1.26(0.88-1.81)$

$0.97(0.74-1.26)$

Retired

Other economically inactive

Ref

$0.80(0.64-0.99)$

$0.78(0.62-0.99)$

$0.71(0.55-0.93)$

$0.79(0.58-1.07)$

eligion

No religion

Christian and other denominators

Muslims

Any other

Ref

$1.34(0.92-1.95)$

$1.35(1.09-1.69)$

$1.05(0.74-1.74)$

\section{Ethnicity}

White

Indian and Pakistani

African-Caribbean

Chinese and other Asian

Other
Ref

$1.12(0.94-1.35)$

$1.15(0.64-2.05)$

$1.00(0.61-1.64)$

\section{Ref}

$2.08(1.23-3.54)$

$2.24(1.61-3.12)$

$1.61(0.85-3.05)$

$1.60(0.78-3.29)$ a. The univariate (Model 1) and partially adjusted (age and gender) (Model 2) odds ratios can be found in online Table DS4. High mental well-being is defined as a Warwick-Edinburgh Mental Well-being Scale (WEMWBS) score of 60-90 and middle-range mental well-being as a WEMWBS score of 43-59. The fully adjusted model included: age, gender, marital status, education, equivalised income, employment, religion and ethnic origin.

b. $P$-value for linear trend $<0.001$

CI 1.09-1.69) were independently associated with an increased odds. Odds of high mental well-being did not differ among other categories of employed and unemployed. Education was not associated with high mental well-being. With reference to the highest income quintile, all other quintiles of equivalised income showed similarly reduced odds of high mental well-being $(\mathrm{OR}=0.80,95 \%$ CI $0.64-0.99$ to $\mathrm{OR}=0.71,95 \%$ CI $0.55-0.93)$; there was no significant trend across categories of income; the lowest group had an odds ratio in the same range as the other groups (OR $=0.79,95 \%$ CI 0.58-1.07). Both Indian and Pakistani $(\mathrm{OR}=2.08$, 95\% CI 1.23-3.54), and African and AfricanCaribbean groups $(\mathrm{OR}=2.24,95 \%$ 1.61-3.12) showed an increased odds of high mental well-being. High mental well-being did not differ by marital status or gender.

Gender-stratified analysis were consistent between men and women for low mental well-being with the exception of education, which was more strongly associated with low mental well-being among women than men, and unemployment, which was not associated with low mental well-being in women (online Table DS5). For high mental well-being, results were consistent between men and women with the exception of retired men and 'other economically inactive' women who had increased odds. Increased odds of high mental well-being among African/African-Caribbean, Indian and Pakistani populations were attributable to increased odds among men (online Table DS6).

\section{Discussion}

\section{Main findings}

These analyses have enabled the comparison of the social and economic correlates of low and high mental well-being in a large, representative sample of the adult English population and show that they do not mirror one another. The results show that the correlates of high mental well-being are different from those of low mental well-being but that the latter closely mirror the correlates of mental illness. Assumptions about socioeconomic determinants made in planning public mental health programmes focusing on the prevention of mental illness may therefore not be applicable to programmes aiming to increase mental well-being.

\section{Measuring mental well-being}

The WEMWBS is used in clinical populations ${ }^{17}$ but is not clinically validated as a measure of mental illness. We have referred to low mental well-being throughout because of this and also in recognition of the debate regarding the relationship between mental well-being and mental illness. Studies based on diagnostic categories of mental illness have shown only moderate correlation (around 0.5) between mental illness and measures of mental wellbeing ${ }^{18}$ consistent with the philosophical position of the dual continuum model.' ${ }^{19}$ Studies based on continuous, clinically validated measures of mental illness however, show a much stronger correlation. For example there is a high inverse correlation between WEMWBS scores and scores on the Center for Epidemiologic Studies Depression Scale (CES-D), a clinically valid measure of depression, widely used in population-based studies. ${ }^{20}$ The latter study examined cut points on the WEMWBS that corresponded to cut points on the CES-D. A WEMWBS score of 42 , which defined the cut point for the low mental well-being group in this study, is below (clinically worse) than a CES-D score of 16 and just above (clinically better) than that consistent with a CES-D score of $26,{ }^{21}$ both cut points which have been used to define clinical populations of varying levels of severity. The bottom $15 \%$ of the WEMWBS distribution - the low mental well-being population in the current study - thus comprised people who were very likely to have scored in the clinical range on self-report measures of common mental disorders and is consistent with estimates of clinically relevant levels of mental illness in the UK population. ${ }^{8,22}$ The odds of low mental wellbeing associated with the socioeconomic factors described in this study also correspond closely to those measured in studies using clinically valid measures of mental illness, ${ }^{9}$ further supporting the view that we have compared the odds for a population very likely to have mental illness with the odds for a population with high mental well-being or positive mental health.

\section{Significance of our findings and comparison with previous studies}

Our findings suggest that socioeconomic factors relate to mental well-being in a way that is not consistent with the way they relate to mental illness. The differences are most striking with regard to 
education and employment where, although we found the correlation with low mental well-being that we expected from studies of mental illness, there was no discernible correlation with high mental well-being, at least for those who were pre-retirement in the employment analyses. If education and employment are key drivers of mental health in general, we would expect to see them correlating as a mirror image with both ends of the mental health spectrum. In a recent analysis of the correlates of well-being, undertaken by the Office of National Statistics and based on their four proxy measures of mental well-being, ${ }^{23}$ people with the highest levels of educational attainment were found to have higher ratings of anxiety than people with lower educational attainment. People in higher managerial and professional occupations also showed higher scores for anxiety than those in lower supervisory and technical occupations. Another recent analysis ${ }^{24}$ of crosssectional studies looking at predictors of mental well-being as measured by the WEMWBS and the short version (SWEMWBS ${ }^{25}$ ) found both employment and education to be significant correlates, but the association with education was non-linear. The latter study was based on linear regression analyses and the findings will therefore have been weighted by the relationship between low mental well-being and education and employment.

Our findings relating to income and high mental well-being are also strikingly different from the linear trend expected from analyses relating to mental illness. The highest quintile income group had better odds of high mental well-being than the other four income groups, but there was nothing to distinguish the latter four groups from one another. It is important to note that the starting point for the highest quintile income bracket was $\left\{47794\right.$, which does not denote great wealth. Other investigators ${ }^{26}$ using linear regression analyses have in general found an association between income and happiness and life satisfaction, both used as proxy measure of mental well-being in economic analyses, that was more evident in the least wealthy groups. In the recent Office of National Statistics analysis based on their four proxy measures ${ }^{23}$ increased earnings were associated with higher levels of life satisfaction, but not with a sense that life was worthwhile, or with happiness. Another analysis of predictors of well-being found that being unsatisfied with personal income was predictive of low mental well-being but less so than being unsatisfied with leisure time. ${ }^{24}$ Mental well-being is more than life satisfaction or happiness. It may be that the latter affective and more transitory components of well-being are influenced by income, whereas the more stable developmental components of mental well-being relating to functioning are not.

Perhaps the most surprising finding, given the well-recognised association between ethnicity and detention under the Mental Health $\mathrm{Act}^{27}$ and the more general association between mental illness and ethnicity, ${ }^{23}$ is the substantially increased odds of high mental well-being among minority ethnic groups, particularly African and African-Caribbean, Indian and Pakistani, and the reduced odds of low mental well-being among African and African-Caribbean groups. The findings relating to African and African-Caribbean populations and mental well-being were also evident in another recent analysis where it was shown, as it was in this study, to be primarily because of high levels in Black men. ${ }^{24}$ These findings are not incompatible with the existing literature. It is possible that minority ethnic populations experience both more severe mental illness of the sort that warrants detention under the Mental Health Act and at the same time more positive mental health than White populations. The WEMWBS has been validated in English-speaking Chinese and Pakistani groups ${ }^{14}$ and shown to be reliable and acceptable, but has not yet been specifically validated in African/AfricanCaribbean populations. This study included only English-speaking populations and findings among those who do not speak English could have been different. The possibility of reporting biases in this self-report measure of mental well-being also needs to be addressed. However, if our findings relating to minority ethnic groups prove robust they are of great interest. Strong arguments are often made on the grounds of social deprivation that healthpromoting interventions should specifically target ethnic minorities. When it comes to improving mental well-being, we may end up needing to learn from these population groups, spreading their knowledge and attitudes to the majority population.

Cross-sectional surveys from which these results derive can point towards possible causal inference but cannot demonstrate it. Our study population was also biased in that respondents differed from the eligible population in that they were more likely to be middle-aged, White, well-educated and relatively wealthy. We would therefore anticipate slightly lower levels of mental illness in the study population and thus arguably lower levels of, and a weaker correlation with, low mental well-being. The fact that correlations with low mental well-being were strong suggests that these biases have not greatly influenced our findings.

Although explanations for our findings must remain speculative, they are compatible with a model in which low mental well-being relates closely to mental illness and both are linearly associated with socioeconomic position through a bidirectional causal relationship - that is poor social and economic circumstances increase the risk of mental illness by increasing personal stressors, but at the same time mental illness increases the risk of poor social circumstances by interfering with social relationships, educational attainment and productivity as it is known to do. ${ }^{1}$ Positive mental health might not be associated so closely with socioeconomic circumstances if causality operated in only one direction, that is positive mental health improves socioeconomic circumstances by supporting educational attainment, productivity and social relationships, but reverse causality does not apply - better social and economic circumstances do not improve positive mental health.

In conclusion, the correlates of positive mental health may be significantly different from the correlates of mental illness. Programmes addressing the social determinants of health are valuable from the point of view of preventing illness, but programmes to improve mental well-being may need to adopt new paradigms that do not rely on prevailing beliefs relating to social inequalities. Warwick Medical School, University of Warwick, Coventry; Preshila Chandimali Samaraweera, MBBS, MSC, MD, Division of Health Sciences, Warwick Medical School, University of Warwick, Coventry and Ministry of Health in Sri Lanka; Frances Taggart, MS, PhD, Ngianga-Bakwin Kandala, PhD, Saverio Stranges, PhD, FFPH, Division of Health Sciences, Warwick Medical School, University of Warwick, Coventry, UK

Correspondence: Sarah Stewart-Brown, Warwick Medical School, University of Warwick, Gibbet Hill Campus Coventry CV4 7AL, UK. Email: sarah.stewart-brown@warwick.ac.uk

First received 3 Mar 2014, final revision 9 Oct 2014, accepted 9 Oct 2014

\section{Acknowledgements} The Health Survey for England was commissioned by the Department of Health and was
carried out by the Joint Health Survey Unit of National Centre for Social Research and Department of Epidemiology and Public Health at University College London. The authors would like to thank all the participants in the Health survey for England 2010 and 2011.

\section{References}

1 Huppert FA. Psychological well-being: evidence regarding its causes and consequences. Appl Psychol Health Well Being 2009; 1:137-64. 
2 Jenkins $\mathrm{R}$, Meltzer $\mathrm{H}$, Jones $\mathrm{PB}$, Brugha $\mathrm{T}$, Bebbington $\mathrm{P}$, Farrell $\mathrm{M}$, et al. Foresight Mental Capital and Wellbeing Project. Mental health: Future challenges. The Government Office for Science, 2008 (http://www.bis.gov.uk/ assets/BISCore/corporate/MigratedD/ec_group/116-08-FO_b.pdf ).

3 HM Government. Healthy Lives Healthy People: Our strategy for Public Health in England. Department of Health, 2010 (https://www.gov.uk/government/ publications/healthy-lives-healthy-people-our-strategy-for-public-health-inengland).

4 HM Government. No Health without Mental Health: A Cross-Governmental Mental Health Outcomes Strategy for People of All Ages. Department of Health, 2011.

5 HM Government. Preventing Suicide in England: One Year on. First Annual Report on the Crossgovernment Strategy to Save Lives. Department of Health, 2014.

6 Chida Y, Steptoe A. Positive psychological well-being and mortality: a quantitative review of prospective observational studies. Psychosom Med 2008; 70: 741-56

7 World Health Organization. Mental Health: New Understanding, New Hope. The World Health Report. World Health Organization, 2001

8 McManus S, Brugha T, Meltzer H, Bebbington P, Jenkins R. Adult Psychiatric Morbidity in England 2007: Results of a Household Survey. Health \& Social Care Information Centre, 2009 (http://www.hscic.gov.uk/ pubs/psychiatricmorbidity07).

9 Fryers T, Melzer D, Jenkins R, Brugha T. The distribution of the common mental disorders: social inequalities in Europe. Clin Pract Epidemiol Men Health 2005; 1: 14

10 Mindell J, Biddulph JP, Hirani V, Stamatakis E, Craig R, Nunn S, et al. Cohort profile: the Health Survey for England. Int J Epidemiol 2012; 41: 1585-93.

11 Tennant R, Hiller L, Fishwick R, Platt S, Joseph S, Weich S, et al. The Warwick-Edinburgh mental well-being scale (WEMWBS): development and UK validation. Health Qual Life Outcomes 2007; 5: 63.

12 HM Government. Improving Outcomes and Supporting Transparency, Part $1 B$. Public health outcomes framework for England, 2013-2016 - Appendices. Department of Health, 2013 (http://www.gov.uk/government/uploads/ system/uploads/attachment data/file/263659/2901502_PHOF_Improving Outcomes_PT1B_v1_1.pdf).

13 Scottish Government. National indicators - mental wellbeing (http:// www.scotland.gov.uk/About/Performance/scotPerforms/indicators/ wellbeing).

14 Taggart F, Friede T, Weich S, Clarke A, Johnson M, Stewart-Brown S Cross cultural evaluation of the Warwick-Edinburgh mental well-being scale (WEMWBS) - a mixed methods study. Health Qual Life Outcomes 2013; 11: 27.
15 Forero CG, Adroher ND, Stewart-Brown S, Castellví P, Codony M, Vilagut G, et al. Differential item and test functioning methodology indicated that item response bias was not a substantial cause of country differences in mental well-being. J Clin Epidemiol 21 Aug 2014 (doi: 10.1016/j.jclinepi.2014.06.017).

16 Health Survey for England. Methodology and Documentation. Data Analysis and Reporting, UK 2011. Health and Social Care Information Centre, 2012.

17 Crawford MJ, Robotham D, Thana L, Patterson S, Weaver T, Barber R, et al. Selecting outcome measures in mental health: the views of service users. J Ment Health 2011; 20: 336-46.

18 weich S, Brugha T, King T, McManus S, Bebbington $\mathrm{P}$, Jenkins $\mathrm{R}$, et al. Mental well-being and mental illness: findings from the Adult Psychiatric Morbidity Survey for England 2007. Br J Psychiatry 2011; 199: 23-8

19 Huppert FA, Whittington JE. Evidence for the independence of positive and negative well-being: implications for quality of life assessment. $\mathrm{Br} J \mathrm{Health}$ Psychol 2003; 8: 107-22.

20 Radloff LS. The CES-D Scale. A self-report depression scale for research in the general population. Appl Psychol Meas1977; 1: 385-401.

21 Bianca D. Performance of the Warwick-Edinburgh Mental Well-Being Scale (WEMWBS) as a Screening Tool for Depression in UK and Italy. Thesis for Doctorate in Psychology, Univeristy of Bologna, 2012 (http:// www2.warwick.ac.uk/fac/med/research/platform/wemwbs/development/ papers/donatella_bianco-thesis.pdf).

22 Singleton N, Bumpstead R, O'Brien M, Lee A, Meltzer. Psychiatric Morbidity amongst Adults Living in Private Households in 2000. TSO (The Stationery Office), 2001.

23 Oguz S, Merad S, Snape D. Measuring National Well-being - What matters Most to Personal Well-being? Office for National Statistics (May 2013) Cross Sectional Analysis of Four Questions. ONS, 2013 (http:// www.ons.gov.uk/ons/rel/wellbeing/measuring-national-well-being/ what-matters-most-to-personal-well-being-in-the-uk-/index.html).

24 McManus S, Chanfreau J, Lloyd C. Predictors of Wellbeing. NatCen, 2013 (http://www.natcen.ac.uk/our-research/research/predictors-of-wellbeing).

25 Stewart-Brown S, Tennant A, Tennant R, Platt S, Parkinson J, Weich S. Internal construct validity of the Warwick-Edinburgh Mental Well-being Scale (WEMWBS): a Rasch analysis using data from the Scottish Health Education Population Survey. Health Qual Life Outcomes 2009; 7: 15.

26 Dolan P, Peasgood T, White M. Do we really know what makes us happy? A review of the economic literature on the factors associated with subjective well-being. J Econ Psychol 2008; 29: 94-122.

27 Singh SP, Burnsa T, Tyrera P, Islama Z, Parsons H, Crawford MJ. Ethnicity as a predictor of detention under the Mental Health Act. Psychol Med 2013; 24: $1-8$.

\section{0 \\ Afflicting spectacle of insanity} years ago

An afflicting spectacle of insanity, followed by a melancholy result, was witnessed a few days ago at the Lunatic Hospital at Saumur. A lady and gentleman went to visit the establishment, accompanied by their child, a little girl of five or six years old As they passed one of the cells, the wretched inmate, an interesting young woman of about 25 , who had irrecoverably lost her reason, through the desertions of a seducer, and the death of their illegitimate offspring, suddenly made a spring at the little girl, who had approached within her reach. In the height of her delirium, the poor creature fancied the stranger's child her own long-lost darling, and, devouring it with kisses, bore it in triumph to the further end of the cell. Entreaties and menaces having proved equally ineffectual to induce her to restore the child to its terrified mother, the director of the establishment was sent for, and, at his suggestion, the maniac was allowed for a few moments to retain peaceable possession of her prize, under the impression that, exhausted with her own frantic violence, she would shortly fall asleep, when the child might be liberated from her grasp without difficulty or the employment of harsh measures. This calculation was not erroneous: in a few minutes, the poor sufferer's eyes closed in slumber, and one of the keepers watching the opportunity, snatched the child from her arms, and restored it to its mother. The shriek of delight uttered by the latter on recovering her treasure awakened the poor maniac, who, on perceiving the child gone, actually howled with despair, and, in a paroxysm of ungovernable frenzy, fell to the ground - to rise no more. Death had released her from her sufferings.

From The Times, 27 October 1837, issue 16558, p. 1. Selected by Rafael Euba. News Syndication UK. Reprinted with permission. 